very similar $(\mathrm{OR}=1.9(0.9-4.0)$ at $<50 \mathrm{~m}$ from a VHV-HVOL)'; 'In that age group, living within $50 \mathrm{~m}$ of the closest VHV-HVOL was significantly associated with $\mathrm{AL}(\mathrm{OR}=2.6(1.0-7.0))$ '; and 'Sensitivity analyses restricted to the best geocoded subjects (uncertainty $\leqslant 20 \mathrm{~m}$ ) generated slightly stronger results $(\mathrm{OR}=2.1(0.9-4.7)$ for living within $50 \mathrm{~m}$ of a VHV-HVOL)'. Inasmuch as all these confidence intervals intersect the 1.0 null value, they must not be interpreted as significant ones. Therefore, the conclusion that 'living $<50 \mathrm{~m}$ from a 225 or $400 \mathrm{kV}$ HVOL may be associated with an increased incidence of childhood AL' is biased by this statistical concern. This situation contains a strong potential to generate confusion, distorts the knowledge, and hampers the understanding of the acute leukaemia aetiology.

\section{REFERENCES}

Sermage-Faure C, Demoury C, Rudant J, Goujon-Bellec S, Guyot-Goubin A, Deschamps F, Hemon D, Clavel J (2013) Childhood leukaemia close to highvoltage power lines - the Geocap study, 2002-2007. Br J Cancer 108: 1899-1906. Szumilas M (2010) Explaining odds ratios. J Can Acad Child Adolesc Psychiatry 19: 227-229.

(c) (i) (2) (2) This work is licensed under the Creative Commons (c) Attribution-NonCommercial-Share Alike 3.0 Unported License. To view a copy of this license, visit http://creativecommons. org/licenses/by-nc-sa/3.0/

\title{
Reply: Comment on 'Childhood leukaemia close to high-voltage power lines - the Geocap study, 2002-2007' - Odds ratio and confidence interval
}

\author{
J Clavel ${ }^{\star, 1,2,3}$ and D Hémon ${ }^{1,2}$ \\ ${ }^{1}$ Inserm U1018, Center for Research in Epidemiology and Population Health (CESP) Equipe 6, Environmental Epidemiology of \\ Cancer Team, 16 Av. Paul Vaillant-Couturier, F-94807 Villejuif, France; ${ }^{2}$ University Paris-Sud, UMRS 1018, F-94807 Villejuif, France \\ and ${ }^{3}$ French National Registry of Childhood Hematological Malignancies (NRCH), Villejuif, France
}

Sir,

Magaña Torres and Gonzalez Garcia (2013) expressed their concern about what they call 'a strong potential (of our conclusions) to generate confusion'. However, we provided the reader all the keys to understand our results and make proper statistical inferences. We reported the details of our analyses, the estimates and their 95\% confidence intervals (CIs), the results of the sensitivity analyses, and our own conclusions were factual. The question we formulated was one-sided ('Is there an increase in childhood AL risk close to HVOL?'), and we let the readers decide whether two-sided tests should be the most relevant for statistical inference, and whether the 95\% CIs should be used for this purpose. In the specific phrases emphasised, we basically commented on the main figures: OR of $1.7(0.9-3.6)$ and 1.9 (0.9-4.0) are close, $2.6(1.0-7.0)$ is a significant association at the 0.05 level of significance (two-sided), 2.1 is slightly higher than 1.7. We think that Magaña Torres and Gonzalez Garcia (2013) overvalue the CIs by using them for decision rules while they are given to quantify the precision of the ORs, whatever the power of the study, the number of tests, the weight of the literature that may influence the actual tests. Given the results, our statement 'In conclusion, the present study has generated additional findings, based on a recent nationwide unselected population-based study, that support the hypothesis that living $<50 \mathrm{~m}$ from a 225 or $400 \mathrm{kV}$ HVOL may be associated with an increased incidence of childhood AL' seems a balanced conclusion.

\section{REFERENCE}

Magaña Torres MT, Gonzalez Garcia JR (2013) Comment on 'Childhood leukaemia close to high-voltage power lines - the Geocap study, 2002-2007' - Odds ratio and confidence interval. Br J Cancer; 109(5): 1384-1385.

(c) (i) (2) This work is licensed under the Creative Commons (c) ${ }_{\text {BY }}$ NG SA Attribution-NonCommercial-Share Alike 3.0 Unported License. To view a copy of this license, visit http://creativecommons. org/licenses/by-nc-sa/3.0/ 